Article

\title{
Provision of School Data and Research Based Teacher Professional Development: Does It Work? Data- and Research-Informed Development of Schools in the Danish "Program for Learning Leadership"
}

\section{Lars Qvortrup}

Danish School of Education, Aarhus University, DK-2400 Copenhagen NV, Denmark; lq@edu.au.dk

Received: 6 March 2019; Accepted: 15 April 2019; Published: 27 April 2019

\begin{abstract}
In the beginning of 2015, a consortium consisting of 13 Danish municipalities with 240 schools, almost 80,000 students and 10,000 professionals together with a university based research institution and a competence development center launched the school development project "Program for Learning Leadership." The project provides data for teachers and school leaders in order to support pedagogical practices and school leadership. It also provides research based competence development packages with professional teams organized in professional learning communities as the central target group for receiving research results and transforming these results into professional practice. Based on a quantitative survey performed in 2015 and repeated in 2017, the project shows that school data and competence development can support positive school changes and improve teachers' professional self-evaluation, and that competence development should focus on professional teams (professional learning communities) rather than on individual teachers. However, it is still too early to identify the effects for students' learning and development achievements.
\end{abstract}

Keywords: school data; competence development; school improvement; professional learning communities; teachers' professional self-evaluation

\section{Introduction: Program for Learning Leadership}

In the beginning of 2015, a consortium consisting of 13 Danish municipalities, the Laboratory for Research-based School Development (LSP) at Aalborg University, and the National Centre for Public Competence Development (COK) launched a school development program with the title "Program for Learning Leadership-Evidence-Informed, Achievement-Oriented Development of Schools and Professional Competencies." The participating municipalities are Billund, Fredericia, Frederikssund, Haderslev, Hedensted, Holbaek, Horsens, Kolding, Nordfyn, Roskilde, Svendborg, Thisted, and Vesthimmerland. Together, the 13 municipalities cover a wide range of Danish municipalities.

With its 13 municipalities, the collaboration represents a total of 240 schools (land registers), almost 80,000 students and 10,000 professionals (teachers, pedagogues, school leaders and administrative staff), which corresponds to approximately $10 \%$ of all Danish primary and lower secondary schools and students. The program is based on a donation of 21 million DKK (USD 3.15 million) from the Maersk Foundation for School Development. The program will run from 2015 to the end of 2019.

The basic idea of the program is the notion that the role of teachers, pedagogues and leaders in the Danish school system can be described as learning leadership: these people are leaders of learning, whether they are standing in the classroom to support student learning, working in teams (professional learning communities), or are a part of the school management.

The goal of the program is for the participating schools to work in accordance with the goals of the national school reform from 2014 of challenging all students to become as accomplished as 
possible, lessening the importance of students' social backgrounds with respect to academic results, and strengthening the trust in and well-being within Danish public schools. A basic precondition for realizing these goals is to increase the quality of and the public respect for professional knowledge and professional practice of teachers.

The program hypothesis is based on the following conditions:

- pedagogical initiatives must be systematically supported by and consciously based on data concerning learning and well-being,

- their starting point must be research based knowledge of the most effective approaches,

- they must be followed up by problem based and practice related professional competence development.

If these three conditions are met, according to the program hypothesis the pedagogical initiatives will lead to a significant and documentable increase of students' learning and well-being, of parents' trust in the school, and of the employees' professional recognition of themselves. This program hypothesis is considered to be an innovative contribution to school development and the strengthening of students' learning and well-being.

The means for reaching this goal is an extensive competence development effort based on the following principles:

- Competence development must be research based, i.e., be based on existing research knowledge about the relationship between pedagogical initiatives and the students' learning and well-being.

- Competence development must be evidence informed, i.e., informed by data concerning the students' learning and well-being collected and analyzed as part of the program.

- Competence development must be collaborative and based on teamwork.

- Competence development must be closely connected to teaching practice.

- Competence development must form a key part of the organizational culture of teachers, pedagogues and school leaders.

It is important to emphasize that it is not sufficient just to "integrate" competence development into existing cultures. If these cultures are resistant to change, nothing will happen. For many years, it has been assumed that the reflective practitioner model based on Donald A. Schön [1] was a convenient model for organizational development, but it has been realized that it may be self-confirming and conservative. As Helen Timperley has stated, "most approaches based in the reflective practitioner model have not demonstrated a significant impact on important outcomes for students because they have not been explicitly focused on evidence about students" [2]. Consequently, reflective practice must be "disturbed" from the outside, while these "disturbances" must also be accepted as important for the organizational culture. This is why competence development must form a "key part." It should not just be "tailored into" existing contexts. In that case, competence development could have a self-confirming effect. The focal point is to ensure that, through research and evidence informed competence development, teachers, pedagogues and school leaders work on a basis of knowledge concerning students' learning and well-being, and ensure that the efforts are focused on objectives of learning, well-being and competencies.

The program provides a research based mapping of students' learning and well-being, which can be used by individual schools or mutually by schools and municipal school administrators as the basis for research informed, targeted management and teamwork cooperation with the intention of developing learning environments increase students' learning and well-being. Every second year an electronic questionnaire for all students, professional staff, school leaders and parents is distributed to all participants of the program. The first survey was done in September-October 2015, and the second, with the same questions, was completed in September-October 2017. In both cases the response rate of students and staff was more than $90 \%$, while the response rate of parents was higher than $50 \%$.

The analyses of the data identify strengths and weaknesses of every participating municipality and every single school concerning dimensions such as learning and wellbeing outcomes, teaching 
quality, professional collaboration, school-home information etc. Data from the questionnaires is used for providing student achievement profiles represented digitally in numerical and graphical formats for every municipality, school and all individual classes. In addition, learning reports are elaborated bi-annually for every municipality. Based on the results, a systematic and goal oriented plan for professional competence development and quality improvement for each school and municipality has been developed.

By choosing research based knowledge about the relationship between pedagogical initiatives and learning achievements as the starting point, this program ensures that the competence development is based on the principle that pedagogical initiatives must be determined by visible learning, i.e., signs of learning achievements. By choosing the mapping of students' learning and well-being as the starting point, the program ensures that the competence development responds to the potentials and challenges in each individual municipality, school and classroom. By making the competence development collective and team based, the program ensures that competence development will not become individual, but will strengthen the professional capital of the entire school. In this way, competence development, school development and development of pedagogical practice are seen as three aspects of the same process.

The Danish "Program for Learning Leadership" has been inspired by similar school development programs in the Ontario and Toronto context following the big school reform process in Ontario from 2004. In the book from 2014 Big-City School Reforms, Michael Fullan and Alan Boyle conclude with six lessons learned, which have all informed the "Program for Learning Leadership" process: we have challenged the status quo by stating that there is no excuse from realizing that by setting goals and developing strategies for realizing these goals, schools can improve their impact on students' learning achievements. We have created a commonly owned strategy by developing a program that includes 240 schools from 13 different municipalities. We have conveyed a high sense of urgency (with data) by pushing each individual school and municipality to setting measurable and realistic goals for achievements. We have developed professional power of capital by providing a number of e-learning based competence development programs. We have had the courage and the legitimacy to intervene, however always in close collaboration with local municipal participants in order to avoid a top-down approach. In addition, we have attended to sustainability, not least by having broad acceptance of the fact that "Program for Learning Leadership" is a five year program and not just a bright idea that will disappear tomorrow. Continuity has been an important dimension of the program [3].

\section{Theoretical Assumptions}

The above assumptions are based on the theory of bounded rationality, developed by Herbert A. Simon in the 1960s and 1970s. This is a basic statement that a professional task such as teaching students is not a simple task, which can be conceptualized in an input-output model, but that it is a complex task. The performance of complex professional tasks is characterized by the condition that the complexity of the task is bigger than the practical capacity of the professional [4]. In systems theoretical terms, one might say that the complexity of the classroom interaction system, which again is structurally coupled to the individual students' learning processes, is greater than the communication capacity of the teacher [5]. Teaching decisions must always be made under the condition of bounded rationality, i.e., that one can never expect to reach a final goal, but must always be ready to revise the decisions made. Feedback and reflexivity are two important ingredients, which again points to the central role of professional judgments.

In Europe, the theory of bounded rationality has led to an even more radical theory of social systems as closed, self-referential systems. In an organizational context this has been developed by the German sociologist Niklas Luhmann, e.g., in this posthumous book Organisation und Entscheidung (Organization and Decision). In a chapter on rationality, he answers the question how the rhetoric of rationality can be understood in autopoietic organizations. The answer is that rationality, as matter of causality based decisions, must be replaced by rationality as construction concerning internally 
based decisions coupling to a context that may react differently than expected. Thus, it is an illusion to expect that every decision leads to a result in accordance with the expectations. Rather, it leads to an unexpected result that forces the decision making organization to make new decisions. Decisions do not lead into predictable effects, they lead into (the necessity of making) new decisions [6]. Similar conclusions can be found in Stacey, Griffin and Shaw's distinction between the "knowable" and the "unknowable" futures of organizations [7].

Accordingly, this idea led to the understanding that modern practicing professions do not just "do" a job or "solve" a task. They solve their tasks based on professional judgments. According to R. K. Merton, three dimensions can be identified in this practice: A "helping," a "doing" and a "knowing" dimension [8]. The "helping" dimension is based on ethical criteria for doing the job. Compared with non-professionals, professionals have an explicit ethical perspective in their practice, while the latter do not. The "doing" dimension is based on a methodologically explicit practice. Again, in comparison, professionals can refer to methodologically explicit principles for their practice, while non-professionals cannot. Finally, the practice of modern professionals is based on a "knowing" dimension: their practice is informed by research based knowledge [8]. Non-professionals do not have access to relevant research based knowledge, and they do not have the professional capacity to make use of research generated knowledge. This implies that research knowledge cannot be conceptualized as an input that can be "translated" into an adequate professional action or method. Research knowledge is one of three "ingredients," which together represent the basic elements for performing an action. The combination of ingredients and the transformation into professional action is the result of professional judgment.

How can this process of judgment be described? This was the question that Donald A. Schön tried to answer. He did so by transforming these considerations into a description of professional practice including not only the practice in itself, but also a single- and double-loop reflection process. Based on Donald Schön's considerations, one could say that performing professionally, e.g., teaching, always includes reflection-in-practice and reflection-on-practice: "reflection-in-practice" represents the ongoing process of self-evaluation of and within the current practice: should I change or modify what I am doing in this very moment? "Reflection-on-practice" represents what happens after or outside the practice, e.g., together with colleagues. Here, the current practice is reflected on with the aim of considering whether it should be methodologically changed, whether the practitioner should qualify him- or herself in new directions, etc. [1].

Currently, these theoretical assumptions have been transformed into theories of professional capital and student improvement oriented school leadership in books such as Andy Hargreaves' and Michael Fullan's Professional Capital [9], which points out that one should combine human and social capital, and Viviane Robinson's Student-Centered Leadership [10], pointing out that the most important leadership precondition for increasing students' school achievements is leading teachers' learning and development.

All these assumptions were taken into consideration by the professional development activities in the "Program for Learning Leadership." It was decided that the teacher team and not the individual teacher should be the core unit of the competence development process, and that research based knowledge should not be "disseminated" to practitioners, but should be of a kind that can be "mobilized," i.e., transformed and translated, by teachers, and that the adequate environment for this mobilization process is so-called professional learning communities [11].

\section{Professional Learning Communities as the Core Unit of the Program}

Professional learning communities have become a fundamental turning point for the development of the Danish primary and secondary school system. With reference to research results (see below), it is widely assumed that learning and wellbeing is best supported when teachers work together in teams, which are directed towards learning and wellbeing, based on open and reflective dialogues and in their practice are closely related to learning and teaching. It is not enough to make big reforms, changing 
rules and structures. One also has to improve the way in which teachers work with and cooperate on developing students' learning and wellbeing. In particular, professional learning and competence development must be rooted in professional learning communities. Professional development is best supported in professional practice, not outside professional practice, i.e., in external courses. Therefore, competence development is provided primarily through e-learning services targeted to teacher teams, with study tasks for the team and with references to teaching practice.

However, although this is the ideal, realities may differ from ideals. In 2012, the Danish researcher Lise Tingleff Nielsen in her PhD thesis on teamwork in the Danish public school pointed out that there is a need to improve the quality of teachers' teamwork [12,13]. She identified three general cultures of teamwork: The first culture is the "family culture". It characterizes a team culture, where teachers meet, have a nice time, but also avoid challenging each other and often do not speak about learning achievements or teaching methods. This may lead to a "conservative" and even "reactionary" professionalism, because teachers may confirm inadequate practices rooted in their professional traditions [14]. The second culture is the "functionality culture". It characterizes a team culture in which the focus of the team is on practical issues. Although it is of course necessary to address these kinds of issues, if the team only focuses on practicalities and not on learning and teaching and on the basic assumptions behind current practices, it may contribute more to status quo than to change and improvement [15]. Therefore, the recommendation is to work in accordance with the principles of professional learning communities.

This phenomenon has a long tradition, not least in an English-speaking educational context. According to Hargreaves and Fullan it seems that the concept was first used in the 1990s by the American educational researcher Shirley Hord [9]. In 1997, she published the book Professional learning communities: Communities of continuous inquiry and improvement [11]. Here, she emphasized two basic qualities of professional learning communities: the participants use an analytical and investigating working approach, and they are constantly devoted to improving their own and their colleagues' professional practice.

A more detailed definition can be found in Concise Answers to Frequently Asked Questions about Professional Learning Communities at Work [16]. According to this book, a professional learning community is "an ongoing process in which educators work collaboratively in recurring cycles of collective inquiry and action research to achieve better results for the students they serve" [17]. In 2006, Stoll et al. published a literature review [18], and since then the concept has been used and developed by researchers around DuFour and Marzano [17,19,20]. In Denmark, an overview of the concept and the phenomenon was published in 2016 [21], but it is not based on a systematic literature review. Additionally, in Denmark, Thomas Albrechtsen has published several books and articles about professional learning communities and supported the spread of the concept in Danish schools and kindergartens [22]. In the "Program for Learning Leadership," professional learning communities is a core organizational unit, not least as the basis for professional competence development.

\section{Professional Learning Communities as a Unit for Competence Development}

According to the North American educational tradition, professional learning communities are supposed to answer six basic questions: (1) What it is we want our students to know? (2) How will we know if our students are learning? (3) How will we respond when students do not learn? (4) How will we enrich and extend the learning for students who are proficient? (5) How will we increase our instructional competence? (6) How will we coordinate our efforts as a school? [20].

In the "Program for Learning Leadership" there has been a particular focus on the fifth of these questions: that the professional learning community is a forum for competence development. The idea is that even though professional learning communities must have a focus on student achievement, it is not productive to provide "what works" recipes to individual teachers. The teaching profession is far too complex for being supported by simple methodological recipes provided by researchers. Research results cannot be directly translated into teaching methods or practices. 
Instead, research based results and practice suggestions must be interpreted and transformed in order to becoming productive in the particular context of an individual school and class. However, interpretation requires interpretation capacity, and such capacity is provided by the professional learning community. Here, a research contribution is transformed from the research community into a professional teaching community, and it is negotiated among the professionals and put into relation to their mutual professional practice, for example through the process of observing and giving feedback to instruction sessions. These processes have been further analyzed and developed in a number of projects and works on research learning communities by Chris Brown [23-25].

In this way, research does not deliver tools and methods, but provides fuel for the social capital of a school or a team of teachers. It enriches the interaction between teachers, and it provides new ways of observing their shared practices.

\section{What Is the Effect of Professional Learning Communities?}

Until now, I have defined and described professional learning communities, and how they work as units of competence development. However, still I have not answered the essential question: do they work? Do they actually contribute to the improved learning and wellbeing of students?

Although Stoll et al. pointed to positive findings concerning the effects of professional learning communities [16], this is not an easy question to answer. It is easier to identify the effect of direct influences, e.g., the effect of specific teaching methods on students' learning achievements. It is less easy to identify the effect of indirect influences, and both professional learning communities and teachers' competence development are sources of indirect influences. The way in which teachers are organized and work together, and their level and type of competence, do not directly affect teaching and, thus, students' learning, wellbeing and development. These factors only affect teaching indirectly, because they constitute the competence based and organizational preconditions for teaching.

However, I can refer to three studies, which all confirm that there is a positive correlation between the organization in professional learning communities and students' learning achievements.

One study was performed by the Icelandic educational researcher Anna Kristin Sigurdardottir. She studied three schools in Iceland. First, she conducted a correlation study, in which she analyzed correlations between the organization of educators and the learning achievements of students. Then, she made an experimental study: at one of the schools they improved the educators' collaboration culture, and in parallel the researchers studied the students' learning achievement. In both parts of the project, it was possible to detect relatively strong evidence concerning a relationship between the level of collaboration in professional learning communities (which was measured according to nine criteria for well functioning professional learning communities) and students' learning outcomes. At the school in which the experimental study was performed, the interventions resulted in higher grades in national tests, particularly in mathematics [26].

The second study was in reality not just one, but a series of studies, which were conducted by the German education researcher Heinz Günter Holtappels together with a number of colleagues at the Institute for School Development Research at Technische Universität in Dortmund. They have studied schools at a number of European countries, and they have, among others, used data from the international TIMSS studies, looking at effects of teaching in mathematics. Additionally, in these studies, indirect methods are employed: One looks at the effects of different aspects of school organization and school culture on the teaching methods, and from here on the secondary effects on learning achievements $[27,28]$. From the studies, it appears that the analyzed professional learning communities achieve high scores concerning goal orientation and focus on students' learning, but lower concerning mutual analyses and improvement of teaching methods. It also appears that there are clear, positive correlations between explicit pedagogical leadership and innovation preparedness and building of teacher teams with a focus on development of teaching methods. It also appears that there are clear, positive correlations between these last two points and well structured and inclusive courses of instruction. The solidly based assumption is that there is a clear link between team collaboration 
organized as professional learning communities and the quality of teaching practice, and thus that professional learning communities are important preconditions for the improvement of students' learning achievements.

I have myself participated in a third study, the so-called FLiK-project in Kristiansand, Norway. In 2013, a comprehensive mapping was conducted based on questionnaires to all students, educators and leaders. Based on the results, problem based competence development and teaching interventions were conducted at all schools and kindergartens in the municipality. In 2015, after the interventions, the comprehensive mapping was repeated. The analyses of the results of the two mappings, among others, show that there is a clear positive correlation between on the one hand the teachers' experience of competence and professional wellbeing, and on the other hand their evaluation of collaboration concerning teaching and students. It is not possible to conclude what comes first, but one can ascertain that teachers who collaborate on teaching and students, also thrive and experience a high level of professional competence. If one makes a comparison of this with the importance of physical maintenance of the school, the latter correlation is much weaker. Thus, it is profitable to invest in strengthening professional collaboration rather than in physical maintenance, if the goal is to improve the wellbeing of the teachers.

Similarly, it appears that there is a clear positive correlation between teachers' professional collaboration and teachers' evaluation of the students' motivation and efforts. Educators who collaborate are teachers, whose students are motivated and have a high work dedication. However, we have not correlated these results with the actual learning achievements measured in e.g., national tests [29]. As in the German studies I referred to, there is clear, although only indirect evidence for a correlation between working in professional learning communities and achieving high results for students' learning, wellbeing and development.

\section{Materials and Methods: Surveys in 2015 and 2017}

After having summarized the results of a number of international studies (from Iceland, Denmark and other European countries) in the final section I will return to the Danish "Program for Learning Leadership" in order to summarize some of the main, preliminary results from this project.

As already mentioned, one of the cornerstones of "Program for Learning Leadership" is the provision of data from all students, staff, leaders and parents. Data has been provided through a survey, which was conducted in September 2015 at the start of the program and repeated in September 2017. However, the surveys are not only used for provision of data to professionals. They are also used for research purposes, i.e., in order to test the effect of the research based interventions during the program: does it have a positive effect for school improvement that data from students, teachers, leaders and parents is made available for all professionals? Does it have a positive effect for school improvement that a number of research based competence development programs are made available for teachers and school leaders working in professional learning communities?

Surveys were conducted in three weeks in September 2015 and again in the same three weeks in September 2017. The survey will be repeated in September 2019. Respondents are all students, staff, leaders and parents. They respond to single item statements on a Likert scale, normally from 1 to 4 . The items are clustered into indexes, using factor structures from earlier projects with the same approach. In order to establish an initial overview, frequency analyses at item level are made for all variables, and factor and reliability analyses are performed using Cronback Alpha. Finally, variance analyses are made, comparing results from 2015 and 2017.

As already mentioned, "Program for learning leadership" is a large, research-informed school development project. This is an important, positive condition for the project, but it also sets limits for the project as a research project. Schools are not randomly chosen, and there is no control group. Consequently, it is possible to register the changes, and to identify correlations between interventions and outcomes. However, these correlations should not be mistaken for causal relations [30]. Furthermore, it must be emphasized that the results are expressions of teachers' self-evaluation. Thus, 
there may also be an element of a Hawthorne effect in the results: It cannot be excluded that the positive result is an effect of taking part in a project with a strong focus on the participants [31].

The main ideas of "Program for Learning Leadership" can also be found in an earlier presentation of the program before the 2017 survey, i.e., before the first results were known [32]. The following analysis is based on data from the 2017 survey report [33].

\section{Response Rates}

Being a "social laboratory," where data is collected not only by and for researchers, but also in order to support the development of schools and pedagogical practices, there is a high degree of "ownership" to the projects from the involved professionals (teachers, pedagogues and school leaders). Consequently, the response rate is extraordinary high, generally $+90 \%$, with the exception of parents with a response rate of approximately $50 \%$. It should also be noticed that the response rates have improved from 2015 to 2017 (Table 1). This supports the assumption of a high level of loyalty and ownership to the school development program.

Table 1. Surveys 2015 and 2017.

\begin{tabular}{cccc}
\hline & Response Rate 2015 & Response Rate 2017 & No. of Respondents 2017 \\
\hline Students & $91 \%$ & $93 \%$ & 69,372 of 74,364 \\
Contact teachers & $97 \%$ & $97 \%$ & 72,426 of 74,364 \\
(evaluation every single student) & $54 \%$ & $52 \%$ & 38,378 of 74,364 \\
Parents & $88 \%$ & $91 \%$ & 6014 of 6581 \\
Teachers & $82 \%$ & $88 \%$ & 1931 of 2182 \\
Pedagogues & $91 \%$ & $99 \%$ & 596 of 603 \\
School leaders &
\end{tabular}

\section{Results}

In this section some of the results from the two surveys will be presented. The results include:

- Teachers' self-evaluation of their professional cooperation and of the teaching quality

- School leaders' evaluation of the work environment (cooperation etc.) and the professional culture at the school and their own priority of time spent on different tasks

- Students' evaluation of teaching quality, class culture, wellbeing and support from teachers

\subsection{Teachers' Self-Evaluation}

Based on the survey from September-October 2015 initiatives were taken concerning school development, and pedagogical practices were modified. Additionally, a number of research-based competence development packages were launched. They were provided not as traditional continuing education programs outside the school, but as digital, multimedia packages used by professionals in their professional teams at the school. Additionally, e-learning and e-support services were provided.

When the survey was repeated in September-October 2017, it was obvious that the level of teachers' self-evaluation had improved —not much, but statistically significant (Table 2)—at a number of dimensions: on average, they were more positive concerning professional cooperation and their ability to provide structure in the classroom, feedback, support and contact to the students and to support students' ability to develop learning strategies (Table 3). 
Table 2. Changes of teachers' self-evaluation.

\begin{tabular}{lcc}
\multicolumn{1}{c}{ Theme } & $\begin{array}{c}\text { Average 2015 } \\
(\mathbf{2 0 1 5 = 5 0 0 )}\end{array}$ & Average 2017 \\
\hline $\begin{array}{l}\text { Cooperation on teaching (shared objectives and } \\
\text { methods, shared planning) }\end{array}$ & 500 & 509 \\
\hline $\begin{array}{l}\text { Cooperation concerning students (cooperation } \\
\text { between teachers and pedagogues) }\end{array}$ & 500 & 512 \\
\hline Provision of structure in the classroom & 500 & 506 \\
\hline Provision of feedback to the students & 500 & 510 \\
\hline Development of learning strategies & 500 & 512 \\
\hline Support and contact to students & 500 & 506 \\
\hline N $=6014.500$ is the average. $100=$ one standard deviation. The scale is known from e.g., PISA scores.
\end{tabular}

Table 3. Number of questions and Cronbach's Alpha.

\begin{tabular}{lcc}
\hline \multicolumn{1}{c}{ Theme } & Number of Questions & Cronbach's Alpha \\
\hline $\begin{array}{l}\text { Cooperation on teaching (shared objectives and } \\
\text { methods, shared planning) }\end{array}$ & 4 & 0.717 \\
\hline $\begin{array}{l}\text { Cooperation concerning students (cooperation } \\
\text { between teachers and pedagogues) }\end{array}$ & 5 & 0.853 \\
\hline Provision of structure in the classroom & 4 & 0.771 \\
\hline Provision of feedback to the students & 4 & 0.780 \\
\hline Development of learning strategies & 5 & 0.778 \\
\hline Support and contact to students & 11 & 0.865 \\
\hline
\end{tabular}

\subsection{School Leaders' Evaluation}

Even more positive results were achieved from the school leaders' evaluation of the work environment of their schools, including elements such as teachers' professional cooperation, the relationship between school leaders and the municipal school administration, and the professional culture of their schools, which includes elements such as shared professional responsibilities among teachers, the ability to differentiate teaching according to students' needs, etc. (Table 4).

Table 4. Changes of school leaders' evaluation.

\begin{tabular}{lcc}
\multicolumn{1}{c}{ Theme } & $\begin{array}{c}\text { Average 2015 } \\
(\mathbf{2 0 1 5}=\mathbf{5 0 0 )}\end{array}$ & Average 2017 \\
\hline $\begin{array}{l}\text { The work environment of the school (professional } \\
\begin{array}{l}\text { cooperation, relationship to municipal school } \\
\text { administration etc.) }\end{array}\end{array}$ & 500 & 523 \\
\hline $\begin{array}{l}\text { The professional culture of the school (shared } \\
\text { professional responsibilities, differentiation of } \\
\text { teaching etc.) }\end{array}$ & 500 & 522 \\
\hline
\end{tabular}

$$
\mathrm{N}=596 .
$$

Similar results were found concerning school leaders' estimation of time spent on different professional tasks. Compared with 2015, they spent more time on supporting their school's vision or objectives, developing their school's professional and educational objectives, and following teachers' implementation of educational objectives in the classroom and the students' academic progress (Table 5).

As already mentioned in the methods section, it should be added that one cannot document a causal relationship between interventions and effects, only a correlational relationship. Additionally, 
one may notice that the school leaders involved in the Learning Leadership Program seem to use more time in 2017 than in 2015 on most of the different tasks. However, the results may be read as a signal of changed priorities in time allocation.

Table 5. School leaders' time spent on tasks.

\begin{tabular}{lcc}
\multicolumn{1}{c}{$\begin{array}{c}\text { How Much Time Have I Spent on the } \\
\text { Following Tasks? }\end{array}$} & Average 2015 & Average 2017 \\
\hline Support my school's visions or objectives & 2.13 & 2.20 \\
\hline $\begin{array}{l}\text { Develop my school's professional and } \\
\text { educational objectives }\end{array}$ & 2.08 & 2.21 \\
\hline $\begin{array}{l}\text { Follow the teachers' implementation of } \\
\text { educational objectives in the classroom }\end{array}$ & 1.81 & 1.94 \\
\hline Follow the students' academic progress & 1.72 & 1.95 \\
\hline Maintain a good “work atmosphere” at the school & 2.64 & 2.62 \\
\hline Take care of administrative duties & 2.54 & 2.51 \\
\hline
\end{tabular}

Little time: 1 . Some time: 2 . Much time: $3 . \mathrm{N}=596$.

\subsection{Students' Evaluation}

Finally, concerning the students' evaluation of teaching and class culture, and their social and academic wellbeing, no statistically significant changes can be identified from 2015 to 2017 (Table 6). As the Danish public school has experienced a tough period since a controversial school reform in 2014, "no changes" may be interpreted as "good news." I would rather interpret the results in relation to the general experience, that big, national school reforms take time. Often, one must wait at least 4-5 years before the first results concerning students' learning and wellbeing emerge [34].

Table 6. Students' evaluation.

Evaluation of teaching and class culture: No statistically significant changes 2015-2017

Evaluation of wellbeing: No statistically significant changes 2015-2017

Minor improvements in the evaluation of "support and interest from teachers"

$$
\mathrm{N}=69,372 \text {. }
$$

\section{Conclusions}

The "Program for Learning Leadership" is an ambitious Danish research-informed school development project, including 240 schools with approximately 10,000 professionals (teachers, pedagogues and school leaders) and with almost 80,000 students. It is based on the assumption that provision of data can support pedagogical practices and school leadership, and that competence development with professional teams organized in professional learning communities as the central target group for receiving research results and transforming these results into professional practice is an important condition for improving schools' professional capital [9].

Based on the results presented in this paper, it can be concluded that,

1. Availability of relevant school data and competence development can improve school changes

2. Availability of relevant school data and competence development can support teachers' professional self-evaluation

3. Competence development should focus on professional teams (professional learning communities) rather than on individual teachers as an important unit.

However, it cannot yet be documented whether the use of data, of competence development and of working in professional learning communities have positive effects on students' evaluation of teaching 
and wellbeing - at least in the short term. Thus, based on data from "Program for Learning Leadership" we cannot yet document a positive effect on students' learning achievements and wellbeing. It is likely that this correlation exists, but we have to wait for the final results in 2019 before such conclusions can be made. See Supplementary Materials.

Supplementary Materials: Supplementary materials can be found on the project website: http://aeringsledelse.dk/ (only in Danish).

Funding: This research received no external funding.

Conflicts of Interest: The author declares no conflict of interest. The founding sponsors had no role in the design of the study; in the collection, analyses, or interpretation of data; in the writing of the manuscript, and in the decision to publish the results.

\section{References}

1. Schön, D.A. The reflective Practitioner. How Professionals Think in Action; Temple Smith: London, UK, 1983.

2. Timperley, H. Realizing the Power of Professional Learning; Open University Press: Cambridge, MA, USA, 2011; p. 8.

3. Fullan, M.; Boyle, A. Big-City School Reforms; Teachers College Press: New York, NY, USA; London, UK, 2014; pp. 142-143.

4. Simon, H.A. The Sciences of the Artificial; MIT Press: Cambridge, MA, USA, 1996.

5. Luhmann, N. Das Erziehungssystem der Gesellschaft; Suhrkamp: Frankfurt am Main, Germany, 2002.

6. Luhmann, N. Organisation und Entscheidung; Westdeutscher Verlag: Opladen, Germany, 2000; pp. 444-472.

7. Stacey, R.D.; Griffin, D.; Shaw, P. Complexity and Management. Fad or radical challenge to systems thinking? Routledge: London, UK; New York, NY, USA, 2000.

8. Merton, R.K. Social Research and the Practicing Professions; Abt Books: Cambridge, MA, USA, 1982.

9. Hargreaves, A.; Fullan, M. Professional Capital: Transforming Teaching in Every School; Routledge: London, UK; New York, NY, USA, 2012.

10. Robinson, V. Student-Centered Leadership; Jossey-Bass: San Francisco, CA, USA, 2011.

11. Hord, S.M. Professional Learning Communities: Communities of Continuous Inquiry and Improvement; Southwest Education Development Laboratory: Austin, TX, USA, 1997.

12. Nielsen, L.T. Teamsamarbejdets Dynamiske Stabilitet-En Kulturhistorisk Analyse af Lxreres Læring i Team; Forlaget UCC: Copenhagen, Denmark, 2013.

13. Warren Little, J. The Persistence of Privacy: Autonomy and Initiative in Teachers' Professional Relations. Teach. Coll. Record 1990, 91, 509-535.

14. Clement, M.; Vandenberghe, R. Teachers' professional development: A solitary or collegial (ad)venture? Teach. Teach. Educ. 2000, 16, 81-101. [CrossRef]

15. Kelchtermans, G. Teacher collaboration and collegiality as workplace conditions. A review. Zeitschrift Pädagogik 2006, 52, 220-237.

16. Mattos, M.; DuFour, R.; DuFour, R.; Eaker, R.; Many, T.W. Concise Answers to Frequently Asked Questions about Professional Learning Communities at Work; Solution Tree Press: Bloomington, IN, USA, 2016; p. 5.

17. DuFour, R.; DuFour, R.; Eaker, R.; Many, T. Learning by Doing. A Handbook for Professional Learning Communities at Work; Solution Tree Press: Bloomington, IN, USA, 2010; p. 11.

18. Stoll, L.; Bolan, R.; McMahon, A.; Wallace, M.; Thomas, S. Professional Learning Communities: A Review of the Literature. J. Educ. Chang. 2006, 7, 221-258. [CrossRef]

19. DuFour, R.; DuFour, R. The School Leader's Guide to Professional Learning Communities at Work; Solution Tree Press: Bloomington, IN, USA, 2012.

20. Marzano, R.J.; Heflebower, T.; Hoegh, J.K.; Warrick, P.; Grift, G. Collaborative Teams that Transform Schools. The Next Step in PLCs; Marzano Research: Bloomington, IN, USA, 2016.

21. Qvortrup, L. Det ved vi om Professionelle Læringsfællesskaber; Dafolo: Frederikshavn, Denmark, 2016.

22. Albrechtsen, T.R.S. Professionelle Læringsfallesskaber-Teamsamarbejde og Undervisningsudvikling; Dafolo: Frederikshavn, Denmark, 2013. 
23. Brown, C. Research Learning Communities: How the RLC Approach Enables Teachers to use Research to Improve Their Practice and the Benefits for Students That Occur as a Result. Res. All 2017, 1, 387-405. [CrossRef]

24. Brown, C. Further exploring the rationality of evidence-informed practice: A semiotic analysis of the perspectives of a school federation. Int. J. Educ. Res. 2017, 82, 28-39. [CrossRef]

25. Brown, C.; Flood, J. Lost in translation? Can the use of theories of action be effective in helping teachers develop and scale up research-informed practices? Teach. Teach. Educ. 2018, 72, 144-154. [CrossRef]

26. Sigurdardottir, A.K. Professional Learning Community in Relation to School Effectiveness. Scand. J. Educ. Res. 2010, 54, 395-412. [CrossRef]

27. Pfeifer, M.; Bos, W.; Holtappels, H.G. Identifying influences of school- and system level factors on student achievement-The German national project of The European Collaborative Research Project ADDITION. Paper presented at the International Congress for School Effectiveness and Improvement (ICSEI), Limassol, Cyprus, 4-7 January 2011.

28. Holtappels, H.G.; Mai, T. Impacts of professional learning communities on student achievement in primary schools. Paper presented at the ECER Conference Istanbul, 9-13 September 2013.

29. Nordahl, T.; Sunnevåg, A.-K.; Qvortrup, L.; Hansen OLekhal, R.; Drugli, M.B. Hold Kursen og Hold ut; FULM Aalborg University Publishers: Aalborg, Denmark, 2016.

30. Hattie, J. Visible Learning. A Synthesis of over 800 Meta-Analyses Relating to Achievement; Routledge: London, UK; New York, NY, USA, 2009.

31. Mayo, E. The Human Problems of an Industrial Civilization; Harvard University Press: Boston, MA, USA, 1946.

32. Qvortrup, L. Capacity Building: Data- and research-informed development of schools and teaching practices in Denmark and Norway. Eur. J. Teach. Educ. 2016, 39, 564-576. [CrossRef]

33. Egelund, N.; Qvortrup, L. Læringsrapport 2017/skoler. Billund, Fredericia, Frederikssund, Haderslev, Hedensted, Holbæk, Horsens, Kolding, Nordfyn, Roskilde, Svendborg, Thisted og Vesthimmerland Kommuner; FULM Aalborg University Publishers: Aalborg, Denmark, 2018.

34. Levin, B. How to Change 5000 Schools; Harvard Education Press: Cambridge, MA, USA, 2008.

(C) 2019 by the author. Licensee MDPI, Basel, Switzerland. This article is an open access article distributed under the terms and conditions of the Creative Commons Attribution (CC BY) license (http://creativecommons.org/licenses/by/4.0/). 